\title{
Environmental Science
}

Cite this: Energy Environ. Sci., 2011, 4, 3878

wwW.rsc.org/ees

PERSPECTIVE

\section{Recent developments of molybdenum and tungsten sulfides as hydrogen evolution catalysts $\dagger$}

\author{
Daniel Merki and Xile $\mathrm{Hu}^{*}$ \\ Received 17th June 2011, Accepted 21st July 2011 \\ DOI: 10.1039/c1ee01970h
}

Recent work shows that nanoparticulate and amorphous molybdenum and tungsten sulfide materials are active catalysts for hydrogen evolution in aqueous solution. These materials hold promise for applications in clean hydrogen production technologies. In this perspective, the syntheses, structures and catalytic activities of nanoparticulate $\mathrm{MoS}_{2}$ and $\mathrm{WS}_{2}$, incomplete cubane-type $\left[\mathrm{Mo}_{3} \mathrm{~S}_{4}\right]^{4+}$ and amorphous $\mathrm{MoS}_{x}$ films are summarized, compared, and discussed.

\section{Introduction}

The release of huge amounts of carbon dioxide into the atmosphere due to combustion of fossil fuels, in addition to the natural $\mathrm{CO}_{2}$-cycle, likely causes and will continue to cause an adverse climate change. Its consequences can only be estimated, but it is now evident that this will have a great impact on the everyday life of humans and on the environment. ${ }^{1}$ Furthermore, fossil fuels as energy sources and energy carriers will be consumed sooner or later, and will not satisfy the future energy demand. These two widely accepted assumptions lead to the conclusion that alternative and renewable energy sources and carriers must be found. Hydrogen is one promising candidate as the energy carrier. ${ }^{2}$

Today, most hydrogen is produced industrially by steam reforming, i.e., the reaction of methane and water to form hydrogen and carbon dioxide. Although there are still enormous amounts of methane on the earth, it is not a renewable energy

Laboratory of Inorganic Synthesis and Catalysis, Institute of Chemical Sciences and Engineering, Ecole Polytechnique Fédérale de Lausanne (EPFL), EPFL-ISIC-LSCI, BCH 3305, Lausanne, CH 1015, Switzerland. E-mail: xile.hu@epfl.ch; Fax: +41 216939305; Tel: +41 216939781

$\dagger$ Electronic supplementary information (ESI) available. See DOI: 10.1039/clee01970h source and the problem of $\mathrm{CO}_{2}$ release is not solved, but shifted from the end-user to the production. A renewable and scalable source for hydrogen would be the splitting of water into oxygen and hydrogen by sunlight. ${ }^{2-4}$

One key step in water splitting is the hydrogen evolution reaction (HER, $2 \mathrm{H}^{+}+2 \mathrm{e}^{-} \rightarrow \mathrm{H}_{2}$ ). With a large enough applied overpotential, which is the excess potential relative to the thermodynamic potential for HER, it is easy to produce hydrogen. Since a large overpotential means a low energy efficiency, operation at a low overpotential is desirable. A good catalyst can reduce the overpotential drastically. Platinum metal is capable of catalyzing HER with significant rate at nearly no overpotential. However, platinum is one of the most expensive metals and has a limited abundance. Nature, on the other hand, evolved hydrogenases as efficient catalysts for hydrogen evolution and oxidation. These hydrogenases use cheap and abundant metals such as iron and nickel for hydrogen production. ${ }^{5}$ Finding a synthetic catalyst composed of such inexpensive materials is a crucial step towards a sustainable 'hydrogen economy'.

Many transition metal complexes such as nickel, iron, and cobalt complexes were reported to homogeneously catalyze the proton reduction. ${ }^{6}$ They are elaborately designed complexes, often inspired by the hydrogenases' active sites, with rather complicated ligands. Molybdenum-sulfur dimers were reported

\section{Broader context}

Tremendous research efforts are now being invested in the search of non-precious hydrogen evolution catalysts. These catalysts can improve the efficiency and lower the cost for sunlight-driven water splitting. Recently, various Mo and W sulfide materials have been shown as very active HER catalysts. Such catalysts are attractive because they are made of abundant and inexpensive elements. This perspective presents these newly emerged and promising HER catalysts. Three classes of Mo and W sulfides are featured, namely, $\mathrm{MoS}_{2}$ and $\mathrm{WS}_{2}$ nanoparticles, a molecular $\left[\mathrm{Mo}_{3} \mathrm{~S}_{4}\right]^{4+}$ complex, and amorphous $\operatorname{MoS}_{x}(X=2$ and 3$)$ films. Their synthesis, structure, and catalytic activity are compared and discussed. The current thinking on the mechanism of hydrogen evolution is outlined. The paper aims to provide a tutorial guide to those who are interested in using group 6 metal chalcogenide materials as HER catalysts for applications in energy fields. 
by Appel et al. as electrocatalysts for the hydrogen production at low overpotentials in organic solvents. ${ }^{7}$

This perspective will focus on molybdenum and tungsten sulfide $\left(\mathrm{MoS}_{x}\right.$ and $\mathrm{WS}_{2}, x \approx 2$ to 3 ) materials as heterogeneous catalysts for HER in water. $\mathrm{MoS}_{2}$ is a well known catalyst for the hydrodesulfurization (HDS) reaction ${ }^{8}$ and is also used as a solid lubricant. ${ }^{9}$ In contrast, $\mathrm{MoS}_{2}$ was for a long time not considered as a promising HER catalyst because bulk $\mathrm{MoS}_{2}$ showed poor activity. ${ }^{10-14}$ In 2005, Hinnemann et al. reported that $\mathrm{MoS}_{2}$ nanoparticles were active HER catalysts. ${ }^{15}$ Since then, the interest in developing and using $\mathrm{MoS}_{2}$ and related metal sulfides such as $\mathrm{WS}_{2}$ as HER catalysts has emerged. Molybdenum and tungsten are non-precious metals and they are relatively abundant and therefore much cheaper than platinum. Molybdenum and tungsten sulfides can be prepared by several methods with different starting reagents, leading to materials with tunable stoichiometry, structure and morphology. The relatively recent discovery of these materials as HER catalysts leaves an open and wide field for research activity. These aspects provoke significant contemporary interest in the investigation and development of $\mathrm{MoS}_{x}$ and $\mathrm{WS}_{2}$ materials as HER catalysts.

The following sections summarize and discuss recent reports of the preparation and catalytic properties of molybdenum and tungsten sulfide materials. First, nanoparticulate $\mathrm{MoS}_{2}$ and $\mathrm{WS}_{2}$ will be presented (Section 2). The study of these well-defined (nano)crystalline materials (contrary to the bulk material) allowed the determination of the catalytically active sites. In section 3 , we will discuss a molecular complex of molybdenum sulfide, so-called incomplete cubane-type $\left[\mathrm{Mo}_{3} \mathrm{~S}_{4}\right]^{4+}$. This complex contains undercoordinated sulfur, which was shown to be the catalytically active site in $\mathrm{MoS}_{2}$ nanoparticles. In Section 4, we will present $\mathrm{MoS}_{2}$ as a highly active co-catalyst in photocatalytic $\mathrm{H}_{2}$ evolution. Amorphous $\mathrm{MoS}_{2}$ and $\mathrm{MoS}_{3}$ films,

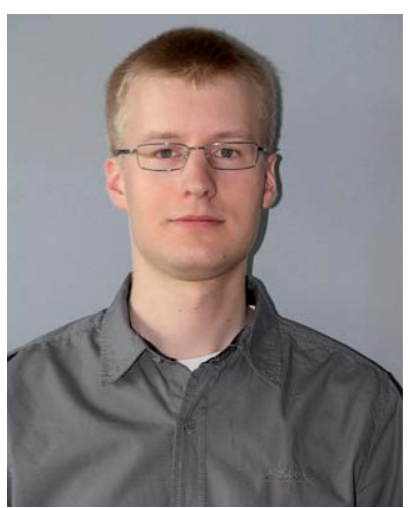

Daniel Merki
Daniel Merki received his BSc and MSc in Chemistry in 2006 and 2008 from the Eidgenössische Technische Hochschule Zürich (ETH Zürich), Switzerland. He is currently a PhD student under the direction of Prof. Xile Hu at the École Polytechnique Fédérale de Lausanne (EPFL) in Switzerland. His thesis work focuses on the development and study of transition metal sulfides, especially molybdenum and tungsten sulfides, as catalysts for the hydrogen evolution reaction. developed and studied in our group, will be discussed in Section 5. Finally, the different $\mathrm{MoS}_{x}$ and $\mathrm{WS}_{2}$ materials will be compared in terms of catalytic activity, cost, and scalability (Section 6).

\section{Nanoparticulate $\mathrm{MoS}_{2}$ and $\mathrm{WS}_{2}$}

\subsection{Synthesis}

Chemical vapor deposition and incipient wetness impregnation are the two most commonly used methods for the preparation of $\mathrm{MoS}_{2}$ and $\mathrm{WS}_{2}$ nanoparticles. Both techniques lead to the same (nano)crystalline material but the atomic-scale structure and morphology are influenced by deposition parameters such as the annealing temperature and the composition of the sulfiding atmosphere. These influences and the role of additional metal atoms such as nickel or cobalt will be discussed in Section 2.2.

In the case of chemical vapor deposition, metallic Mo is typically deposited onto $\mathrm{Au}(111)$ in a sulfiding atmosphere $\left(\mathrm{H}_{2} \mathrm{~S}\right)$ of around $10^{-6} \mathrm{mbar}$ at $400 \mathrm{~K}$. The sample is subsequently annealed at temperatures between $673 \mathrm{~K}$ and $823 \mathrm{~K}$ for $15 \mathrm{~min}$ while maintaining the sulfiding atmosphere. ${ }^{16-18} \mathrm{MoS}_{2}$ microcrystals can also be grown through chemical vapor transport from $\mathrm{MoS}_{2}$ powder. ${ }^{19}$ The $\mathrm{MoS}_{2}$ powder and an excess of sulfur are placed in one end of a quartz tube which is then evacuated and sealed. This end of the tube is heated to $963 \mathrm{~K}$ or higher while the opposite end is kept at $818 \mathrm{~K} .{ }^{19}$

For the incipient wetness impregnation method, aqueous solutions of either $\left(\mathrm{NH}_{4}\right)_{6} \mathrm{Mo}_{7} \mathrm{O}_{24} \cdot 4 \mathrm{H}_{2} \mathrm{O}$ (for $\mathrm{MoS}_{2}$ ), $\mathrm{H}_{24} \mathrm{~N}_{6} \mathrm{O}_{39} \mathrm{~W}_{12} \cdot x \mathrm{H}_{2} \mathrm{O}$ (for $\left.\mathrm{WS}_{2}\right),{ }^{20}$ or $\left(\mathrm{NH}_{4}\right)_{2}\left[\mathrm{MS}_{4}\right](\mathrm{M}=$ Mo or $\mathrm{W}$, for $\mathrm{MoS}_{2}$ and $\left.\mathrm{WS}_{2}\right)^{21}$ are used to impregnate the support material, e.g. Toray carbon paper $^{20}$ or carbon powder. ${ }^{21}$ The samples are first dried in air at temperatures higher than $373 \mathrm{~K}$. Afterwards, the samples are treated with $10 \% \mathrm{H}_{2} \mathrm{~S}$ in $\mathrm{H}_{2}$ for

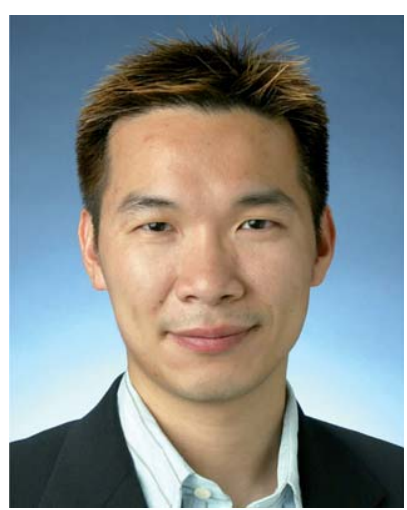

Xile Hu
Xile Hu was born in 1978 in Fujian, China. He received a $B$. $S$. degree from Peking University (June 2000) and a PhD degree from the University of California, San Diego (December 2004), both in chemistry. His dissertation "Metal Complexes of Tripodal $\mathrm{N}$-Heterocyclic Carbene Ligands: Synthesis, Structure, Bonding, and Reactivity" was guided by Prof. Karsten Meyer. He became a postdoctoral scholar in the group of Prof. Jonas C. Peters at the California Institute of Technology in February 2005. At Caltech, he worked on Co-catalyzed hydrogen evolution. In 2007, he was appointed as a tenure-track assistant professor of chemistry at the École Polytechnique Fédérale de Lausanne (EPFL) in Switzerland. His research interest is on the development of catalysts based on earth-abundant elements for applications in synthesis and in energy and sustainability. 
either 4 hours at $723 \mathrm{~K},{ }^{20}$ or 6 hours at $1073 \mathrm{~K} .{ }^{21}$ Cobalt- and nickel-promoted $\mathrm{MoS}_{2}$ and $\mathrm{WS}_{2}$ are made by co-impregnation of two solutions (W/Mo solution with an aqueous solution of $\left.\mathrm{C}_{4} \mathrm{H}_{4} \mathrm{CoO}_{4} \cdot 4 \mathrm{H}_{2} \mathrm{O}\right)^{20}$ or by adding the appropriate metal ion (Co (acetate $)_{2}$ or $\mathrm{Ni}(\text { acetate })_{2}$ ) to the impregnation solution. ${ }^{21}$

\subsection{Structure}

A single crystal of molybdenite, the mineral of molybdenum disulfide, has a hexagonal structure. Tungstenite is isomorphous to molybdenite but is of rare occurrence. ${ }^{22}$ However, $\mathrm{MoS}_{2}$ and $\mathrm{WS}_{2}$ nanocrystals exhibit a triangular morphology and are often reported as slightly truncated triangles. ${ }^{16-18,21}$ Fig. 1 shows one of the first scanning tunneling microscopy (STM) images of $\mathrm{MoS}_{2}$ clusters on $\mathrm{Au}(111) .{ }^{16}$ In the atomic-scale structure, the basal plane is parallel to the $\mathrm{Au}(111)$ surface and the edge sites lie at the edge of the nanoparticles. The hexagonal structure of $\mathrm{MoS}_{2}$ contains two different edge sites, the (1010) S edge and the (1010) Mo edge. Since the nanoclusters have a triangular shape, only one edge type can be present. It was found that Mo edges terminate the structure. ${ }^{16-18,21}$ The atomic ball model in Fig. 2 shows a hypothetical, bulk-truncated $\mathrm{MoS}_{2}$ hexagon exposing the two types of edges (in color). ${ }^{17}$ Together with the additional corners (no filling), the structure shows the triangular morphology with the terminating Mo edges. The Mo edges would be unstable if they were not at least partially covered with sulfur. Therefore, $\mathrm{S}$ atoms are adsorbed on the (1010) edges to form partially $(50 \%)$ or fully $(100 \%)$ covered Mo edges (Fig. 2, left).

Lauritsen et al. could alter the morphology between triangular and hexagonal by changing the $\mathrm{H}_{2} \mathrm{~S}: \mathrm{H}_{2}$ ratio in the sulfiding atmosphere during chemical vapor deposition. ${ }^{17}$ Synthesis in $\mathrm{H}_{2} \mathrm{~S}: \mathrm{H}_{2}=500$ yielded triangular $\mathrm{MoS}_{2}$ nanoclusters terminated by fully saturated Mo edges, whereas sulfiding in $\mathrm{H}_{2} \mathrm{~S}: \mathrm{H}_{2}=0.07$ resulted in hexagonally truncated nanoclusters exposing two different types of edges, 50\% covered Mo edges and fully sulfursaturated $\mathrm{S}$ edges with $\mathrm{H}$ atoms adsorbed.

The particle size can also be influenced by the annealing temperature. Jaramillo et al. showed that sintering at a higher temperature $(823 \mathrm{~K})$ led to larger nanoclusters than annealing at

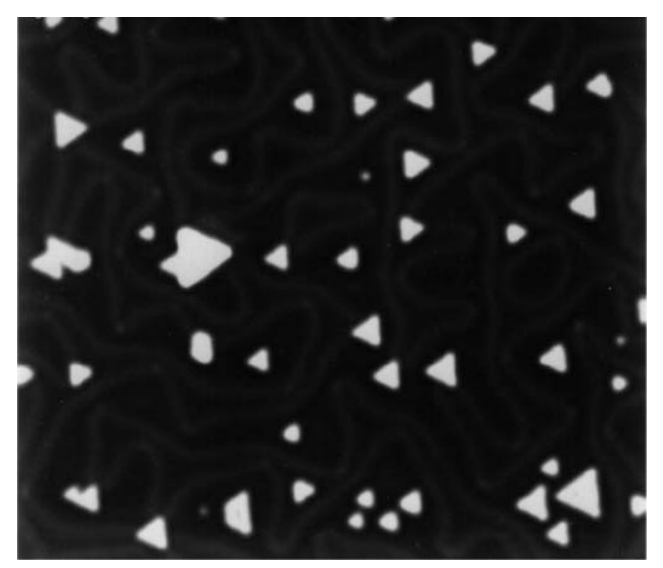

Fig. 1 STM image $(744 \AA \times 660 \AA$ ) of sulfided Mo clusters on $\mathrm{Au}(111)$. (Reprinted with permission from ref. 16. Copyright (2000) by the American Physical Society.)

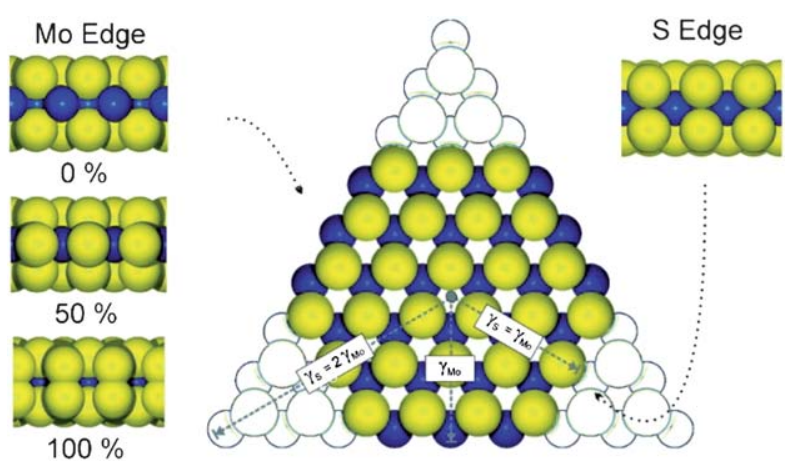

Fig. 2 Atomic ball model showing a hypothetical, bulk-truncated $\mathrm{MoS}_{2}$ hexagon exposing the two types of low-index edges, the $\mathrm{S}$ edges and Mo edges (see main text for details). Mo atoms are blue, $\mathrm{S}$ atoms yellow. (Reprinted from ref. 17, Copyright (2004), with permission from Elsevier.)

lower temperature $(673 \mathrm{~K}) .{ }^{18}$ Since the predominance of Mo edges is the same in both cases, the ratio of basal plane sites to edge sites changes with the particle size without altering the nature of the edges. This fact is important for the HER activity and will be further discussed in Section 2.3.

Incorporation of a sub-stoichiometric amount of cobalt or nickel to $\mathrm{MoS}_{2}$ and $\mathrm{WS}_{2}$ changes the morphology of the nanoparticles remarkably. Co or $\mathrm{Ni}$ promoted $\mathrm{MoS}_{2}$ is found as heavily truncated triangles exposing the $\mathrm{S}$ edge predominantly, whereas the unpromoted $\mathrm{MoS}_{2}$ nanoparticles are only slightly truncated triangles with Mo edges. ${ }^{20,21}$ The change in morphology is explained with the preference of promoter atoms to be located exclusively at the S edges, as demonstrated by STM studies and density functional theory (DFT) computations. ${ }^{20,23}$

\subsection{HER activity}

Molybdenum disulfide is a highly active HDS catalyst and the (Mo) edge sites of the nanoparticles are known to be catalytically active in unpromoted as well as in promoted $\mathrm{MoS}_{2} \cdot{ }^{17,19,21,23,24}$ Furthermore, Helveg et al. reported that sulfur vacancies on the Mo edges must be formed before HDS can take place, i.e. the $\mathrm{S}$ coverage of Mo edges must be less than $50 \%{ }^{16}$

In DFT studies, ${ }^{15}$ the free energy of adsorbed $\mathrm{H}\left(\Delta G_{\mathrm{H}}\right)$ on crystalline $\mathrm{MoS}_{2}$ (10) 10 ) edge sites with $50 \% \mathrm{~S}$ adsorption was shown to be close to those on a hydrogenase model and platinum, i.e. close to zero. Therefore it was concluded that nanocrystalline $\mathrm{MoS}_{2}$, or more precisely its (1010) edge sites, should be a good catalyst for hydrogen evolution. This was experimentally demonstrated by Jaramillo et al. in 2007. ${ }^{18}$ As described in Section 2.2, they synthesized $\mathrm{MoS}_{2}$ nanoparticles of different sizes on $\mathrm{Au}(111)$. Furthermore, samples with varying surface coverage were prepared. With the help of STM images two quantities could be determined for each sample: the $\mathrm{MoS}_{2}$ area coverage $\left(\mathrm{nm}_{\mathrm{MoS}_{2}}^{2} / \mathrm{nm}_{\text {geometric }}^{2}\right)$ and the $\mathrm{MoS}_{2}$ edge length $\left(\mathrm{nm}_{\mathrm{MoS}_{2}} / \mathrm{nm}_{\text {geometric }}^{2}\right)$. The electrochemically measured exchange current densities for the HER on each sample were normalized by both quantities (Fig. 3). It can be seen that the exchange current density is proportional to the length of edge sites, but not to the area coverage. This demonstrates that the edge site is indeed the catalytically active site. Exchange current densities $\left(j_{0}\right)$ 

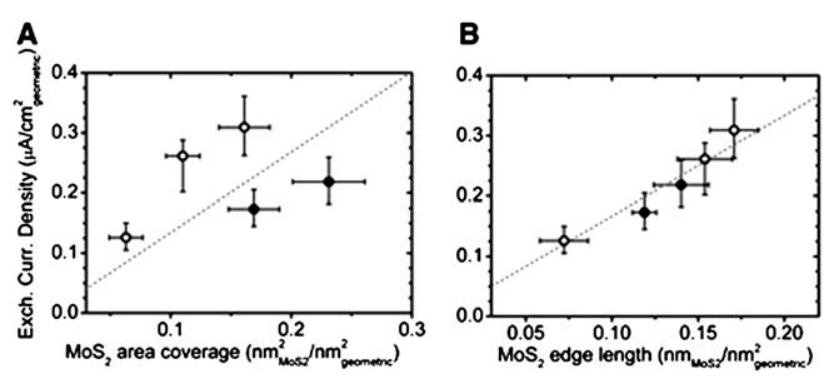

Fig. 3 Exchange current density versus (A) $\mathrm{MoS}_{2}$ area coverage and (B) $\mathrm{MoS}_{2}$ edge length (see main text for details). (From ref. 18. Reprinted with permission from AAAS.)

in the range of $1.3 \times 10^{-7}$ to $3.1 \times 10^{-7} \mathrm{~A} \mathrm{~cm}_{\text {geometric }}^{-2}$ and Tafel slopes of 55 to $60 \mathrm{mV} \mathrm{dec}{ }^{-1}$ were found for all $\mathrm{MoS}_{2}$ samples. The sample annealed at $673 \mathrm{~K}$ with the highest $\mathrm{MoS}_{2}$ area coverage revealed a current density of $c a .0 .2 \mathrm{~mA} \mathrm{~cm}$ geometric at $150 \mathrm{mV}$ overpotential. Turnover frequency (TOF) numbers per active site were determined and found to be $0.02 \mathrm{~s}^{-1}$ at $0 \mathrm{mV}$ overpotential, assuming that each edge site is active on a close-packed surface. This TOF is rather high for metals, and is not much lower than that of platinum $\left(\mathrm{TOF}=0.9 \mathrm{~s}^{-1}\right) .{ }^{18}$

Bonde et al. reported the HER activity of unpromoted and cobalt promoted nanoparticulate $\mathrm{MoS}_{2}$ and $\mathrm{WS}_{2}$ on a carbon support. ${ }^{20}$ Unpromoted $\mathrm{MoS}_{2}$ has an exchange current density of

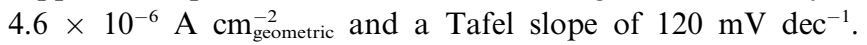
Unpromoted $\mathrm{WS}_{2}$, Co promoted $\mathrm{MoS}_{2}$ and Co promoted $\mathrm{WS}_{2}$ showed Tafel slopes of 135,101 and $132 \mathrm{mV} \mathrm{dec}^{-1}$, respectively, but the exchange current densities were not reported. By comparing the current densities at a given overpotential, it is found that unpromoted $\mathrm{WS}_{2}$ is almost as active as unpromoted $\mathrm{MoS}_{2}$, and that cobalt is promoting the catalytic activity of both $\mathrm{MoS}_{2}$ and $\mathrm{WS}_{2}$. At $300 \mathrm{mV}$ overpotential, unpromoted $\mathrm{MoS}_{2}$, unpromoted $\mathrm{WS}_{2}$, Co promoted $\mathrm{MoS}_{2}$ and Co promoted $\mathrm{WS}_{2}$ have current densities of ca. 1.5, 1.0, 4.0 and $5.5 \mathrm{~mA} \mathrm{~cm}_{\text {geometric }}^{-2}$, respectively. These numbers were found during the initial scans of polarization measurements at $\mathrm{pH}=0.4$. The current densities at the same overpotential in the final scans are lower, being $c a$. $0.4,1.5$ and $2 \mathrm{~mA} \mathrm{~cm}-2$ geometric for unpromoted $\mathrm{WS}_{2}$, Co-promoted $\mathrm{MoS}_{2}$ and Co-promoted $\mathrm{WS}_{2}$, respectively. For unpromoted $\mathrm{MoS}_{2}$ the final scan was not shown. ${ }^{20}$

Li et al. recently reported $\mathrm{MoS}_{2}$ nanoparticle on reduced graphene oxide $\left(\mathrm{MoS}_{2} / \mathrm{RGO}\right)$ as an active catalyst for HER. ${ }^{25}$ The catalyst was prepared by a solvothermal reaction of $\left(\mathrm{NH}_{4}\right)_{2} \mathrm{MoS}_{4}$ and hydrazine in a DMF solution of oxidized graphene at $473 \mathrm{~K}$. They loaded an amount of $c a .285 \mu \mathrm{g} \mathrm{cm}^{-2}$ of $\mathrm{MoS}_{2} / \mathrm{RGO}$ on the glassy carbon. Polarization measurements of the modified electrode in $0.5 \mathrm{M} \mathrm{H}_{2} \mathrm{SO}_{4}$ yielded a current density of $c a .9 \mathrm{~mA} \mathrm{~cm}^{-2}$ at $150 \mathrm{mV}$ overpotential and $c a .30 \mathrm{~mA} \mathrm{~cm}^{-2}$ at $200 \mathrm{mV}$ overpotential. In the subsequent Tafel analysis a Tafel slope of $41 \mathrm{mV} \mathrm{dec}{ }^{-1}$ was found. RGO alone showed no HER activity in the mentioned potential region and the $\mathrm{MoS}_{2}$ nanoparticles alone revealed a current density of $c a .1 \mathrm{~mA} \mathrm{~cm}^{-2}$ at 200 $\mathrm{mV}$ overpotential. At the same overpotential, $\mathrm{MoS}_{2}$ nanoparticles physically mixed with carbon black $(7: 3 \mathrm{w} / \mathrm{w})$ showed a current density of $c a .7 \mathrm{~mA} \mathrm{~cm}^{-2}$. The high geometric activity of $\mathrm{MoS}_{2} / \mathrm{RGO}$ is largely due to the high catalyst loading $(285 \mu \mathrm{g}$ $\mathrm{cm}^{-2}$ ). The higher activity of $\mathrm{MoS}_{2} / \mathrm{RGO}$ compared to $\mathrm{MoS}_{2} /$ graphite was attributed to the stronger chemical and electronic coupling between the graphene sheets and $\mathrm{MoS}_{2}$, because these couplings lead to small sized and highly dispersed $\mathrm{MoS}_{2}$ nanoparticles and allow rapid electron transport from the less-conducting $\mathrm{MoS}_{2}$ nanoparticles to the electrode. ${ }^{25}$

\section{Incomplete cubane-type $\left[\mathrm{Mo}_{3} \mathrm{~S}_{4}\right]^{4+}$}

After the identification of the catalytically active site in (nano) crystalline $\mathrm{MoS}_{2}$, a molecular $\mathrm{MoS}_{x}$ compound, featuring similar sites, was studied by Jaramillo et al. ${ }^{26}$ The so-called supported incomplete cubane-type $\left[\mathrm{Mo}_{3} \mathrm{~S}_{4}\right]^{4+}$ clusters were investigated for their HER activity. Jaramillo et al. synthesized the $\left[\mathrm{Mo}_{3} \mathrm{~S}_{4}\right]^{4+}$-type complex $\left(\left[\mathrm{Mo}_{3} \mathrm{~S}_{4}\left(\mathrm{H}_{2} \mathrm{O}\right)_{9}\right]^{4+}\right)$ by reduction of either $\left(\mathrm{NH}_{4}\right)_{2}\left[\mathrm{MoS}_{4}\right]$ or $\left[\mathrm{Mo}_{2} \mathrm{O}_{2} \mathrm{~S}_{2}\left(\mathrm{H}_{2} \mathrm{O}\right)_{6}\right]^{2+}$ with sodium borohydride and immobilized it on a Toray graphite paper disk and highly oriented pyrolytic graphite (HOPG), respectively. The HOPG surface had to be activated into a hydrophilic form to absorb $\left[\mathrm{Mo}_{3} \mathrm{~S}_{4}\right]^{4+}$.

The molecular structure of the $\left[\mathrm{Mo}_{3} \mathrm{~S}_{4}\right]^{4+}$ complex is shown in Fig. 4. It exhibits similarities with the molybdenum sulfur clusters investigated by Niemantsverdriet et al. ${ }^{27}$ It contains undercoordinated sulfur, which was shown to be the active site of $\mathrm{MoS}_{2}$ nanoparticles for HER. ${ }^{15,18}$ STM images of HOPG supported $\left[\mathrm{Mo}_{3} \mathrm{~S}_{4}\right]^{4+}$ showed that individual $\left[\mathrm{Mo}_{3} \mathrm{~S}_{4}\right]^{4+}$ moieties (together with the anions) were uniformly scattered on the HOPG surface. It was therefore possible to determine the number of clusters and to calculate the TOF per cluster.

Tafel analysis of polarization measurements of a $\left[\mathrm{Mo}_{3} \mathrm{~S}_{4}\right]^{4+}$ submonolayer on the activated HOPG in $0.5 \mathrm{M} \mathrm{H}_{2} \mathrm{SO}_{4}$ yielded an exchange current density of $2.2 \times 10^{-7} \mathrm{~A} \mathrm{~cm}_{\text {geometric }}^{-2}$ and a Tafel slope of $120 \mathrm{mV} \mathrm{dec}{ }^{-1}$. The TOF per $\left[\mathrm{Mo}_{3} \mathrm{~S}_{4}\right]^{4+}$ cation was found to be $0.07 \mathrm{~s}^{-1}$. Although the exact numbers of active sites per $\left[\mathrm{Mo}_{3} \mathrm{~S}_{4}\right]^{4+}$ is not known, this TOF is on the same order of magnitude as the TOF of nanoparticulate $\mathrm{MoS}_{2}$. However, HOPG supported $\left[\mathrm{Mo}_{3} \mathrm{~S}_{4}\right]^{4+}$ loses its catalytic activity for HER during consecutive polarization measurements. The decrease in activity was most likely due to cathodic desorption of the clusters. Indeed, little or no Mo was left on the surface after these polarization measurements, according to X-ray photoelectron spectroscopy (XPS) data. The modified graphite paper disk was used as an electrode in a membrane electrode assembly to test the ability of $\left[\mathrm{Mo}_{3} \mathrm{~S}_{4}\right]^{4+}$ to catalyze the hydrogen oxidation reaction

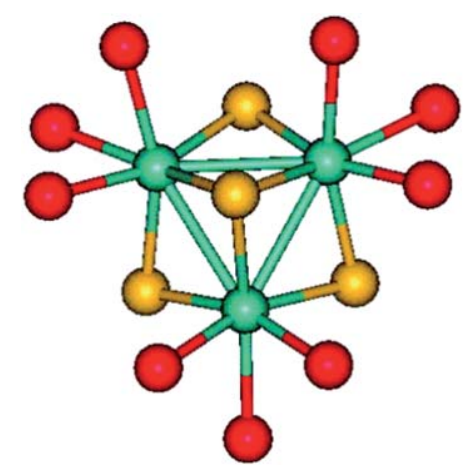

Fig. 4 Molecular structure of $\left[\mathrm{Mo}_{3} \mathrm{~S}_{4}\right]^{4+}$. Mo atoms are blue, $\mathrm{S}$ atoms yellow and $\mathrm{O}$ atoms (from water ligands) red. (Reprinted with permission from ref. 26. Copyright 2008 American Chemical Society.) 
(HOR). No HOR activity was found. ${ }^{29}$ In the same setup, the first polarization curve in the cathodic region showed current densities for HER of ca. 2.5, 5.5 and $16.5 \mathrm{~mA} \mathrm{~cm}_{\text {geometric }}^{-2}$ at 150 , 200 and $300 \mathrm{mV}$ overpotential, respectively. During the $10^{\text {th }}$ sweep, the current densities at the same overpotentials were significantly lower, being $c a .1 .5,3$ and $12 \mathrm{~mA} \mathrm{~cm}$ geometric, respectively.

\section{4. $\mathrm{MoS}_{2}$ in photocatalytic $\mathrm{H}_{2}$ evolution}

The use of solar energy, a renewable energy resource, for water splitting is desirable. Through this process, the energy of sun is stored in the chemical bonds. ${ }^{4}$ Most systems for photocatalytic hydrogen production use $\mathrm{TiO}_{2}$ as photocatalyst, often combined with other semiconductors like $\mathrm{CdS}$ and a co-catalyst, e.g. platinum. Great efforts are made to increase the photocatalytic activity of these systems, either by changing the nanostructure of the electrode materials ${ }^{30}$ or by searching for different and more active photocatalysts than $\mathrm{TiO}_{2}{ }^{31}$

Molybdenum and tungsten disulfide are not photocatalysts for HER. Under irradiation and in the presence of photosensitizers, however, they show activity for hydrogen evolution. ${ }^{14,32}$ Sobczynski et al. synthesized $\mathrm{SiO}_{2}$ supported $\mathrm{WS}_{2}\left(\mathrm{WS}_{2} / \mathrm{SiO}_{2}\right)^{14}$ and $\mathrm{MoS}_{2}\left(\mathrm{MoS}_{2} / \mathrm{SiO}_{2}\right) .{ }^{32}$ These samples were used as HER catalysts in a $0.1 \mathrm{M} \mathrm{KOH}$ aqueous slurry together with $\mathrm{CdS} / \mathrm{SiO}_{2}$ as sensitizer and methanol as a sacrificial electron donor. Under irradiation, both mixtures produced hydrogen. Hydrogen evolution rates up to 15 and $6 \mathrm{ml} \mathrm{H}_{2}$ per hour (referred to $1 \mathrm{~g}$ catalyst) for $\mathrm{MoS}_{2} / \mathrm{SiO}_{2}$ and $\mathrm{WS}_{2} / \mathrm{SiO}_{2}$, respectively, were reported. These rates correspond to TOFs of $c a$. 0.6 and $0.2 \mathrm{~h}^{-1}$, referred to one unit of $\mathrm{MoS}_{2}$ and $\mathrm{WS}_{2}$, respectively. Compared to $\mathrm{Pt} / \mathrm{SiO}_{2}, \mathrm{WS}_{2} / \mathrm{SiO}_{2}$ and $\mathrm{MoS}_{2} / \mathrm{SiO}_{2}$ showed better hydrogen evolution activity and stability under the same conditions. Since $\mathrm{MoS}_{2} / \mathrm{SiO}_{2}$ was prepared by thermal decomposition of $\mathrm{MoS}_{3} /$ $\mathrm{SiO}_{2}$, slightly different $\mathrm{MoS}_{2} / \mathrm{SiO}_{2}$ samples could be made by varying the annealing temperature. ${ }^{32} \mathrm{MoS}_{3} / \mathrm{SiO}_{2}$ was decomposed and calcined either in argon or hydrogen at 623,673 or 723 K. It was shown that the catalytic activity of $\mathrm{MoS}_{2} / \mathrm{SiO}_{2}$ decreased with a rise of calcination temperature. This effect was explained by a higher amount of structural defects on the surface, which are the catalytically active sites, for the samples annealed at a lower temperature.

Zong et al. deposited $\mathrm{MoS}_{2}$ nanoparticles directly on the photosensitizer $\mathrm{CdS}\left(\mathrm{MoS}_{2} / \mathrm{CdS}\right) .{ }^{28}$ The sample was prepared by impregnating CdS with an aqueous solution of $\left(\mathrm{NH}_{4}\right)_{2}\left[\mathrm{MoS}_{4}\right]$, followed by a treatment in $\mathrm{H}_{2} \mathrm{~S}$ flow at temperatures from 443 to $773 \mathrm{~K}$ for 2 hours. Fig. 5 shows a high-resolution transmission electron microscopy (HRTEM) image of $\mathrm{MoS}_{2} / \mathrm{CdS}$ prepared at $773 \mathrm{~K}$ with $1 \mathrm{wt} \%$ loading of $\mathrm{MoS}_{2}$. Photocatalytic reactions were carried out with an aqueous suspension of $\mathrm{MoS}_{2} / \mathrm{CdS}$ using lactic acid as a sacrificial agent. The highest rate of hydrogen evolution on $\mathrm{MoS}_{2} / \mathrm{CdS}$ was achieved when the loading amount of $\mathrm{MoS}_{2}$ on CdS was about $0.2 \mathrm{wt} \%$. For an amount of $0.1 \mathrm{~g}$ catalyst $\left(\mathrm{MoS}_{2} / \mathrm{CdS}\right)$, the rate of hydrogen evolution was $c a .520$ $\mu \mathrm{mol} \mathrm{h} \mathrm{h}^{-1}\left(\mathrm{TOF} \approx 420 \mathrm{~h}^{-1}\right){ }^{33}$ When the loadings of $\mathrm{MoS}_{2}$ are small, the activity increased with an increase in loading. There is an optimal loading, and further increases of loading led to lower activity. This observation suggests that the contact between $\mathrm{CdS}$ and $\mathrm{MoS}_{2}$ is crucial for the electron transfer between the two

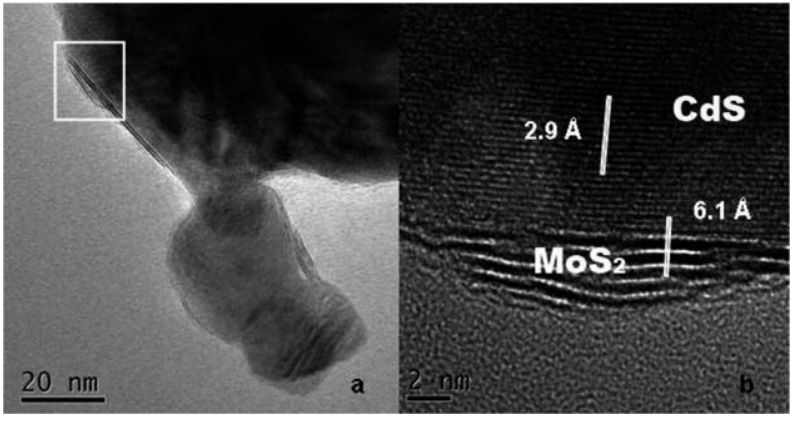

Fig. 5 (a) HRTEM image of $1 \mathrm{wt} \% \mathrm{MoS}_{2} / \mathrm{CdS}$ prepared at $733 \mathrm{~K}$ and (b) the magnified HRTEM image of the selected frame from image (a) (see main text for details). (Reprinted with permission from ref. 28. Copyright 2008 American Chemical Society.)

components. ${ }^{28}$ Therefore, the $\mathrm{MoS}_{2}$ layer should neither be too thick nor should it cover a large portion of the surface of CdS.

Comparison was made to $\mathrm{CdS}$ particles loaded with other HER catalysts such as $\mathrm{Pt}, \mathrm{Ru}, \mathrm{Rh}, \mathrm{Pd}$ and $\mathrm{Au}$. The rate of hydrogen evolution on $\mathrm{MoS}_{2} / \mathrm{CdS}$ was higher than on all other metal/CdS photocatalysts (Fig. 6). This result was again explained by the better electric contact between $\mathrm{MoS}_{2}$ and CdS.

Zong et al. also used colloidal $\mathrm{MoS}_{2}$ nanoparticles as catalyst for visible light driven hydrogen production. ${ }^{34}$ Contrary to the hydrogen evolution systems discussed above, the reactions were not studied in an aqueous solution but in a $2: 1$ acetonitrilemethanol solution. The colloidal $\mathrm{MoS}_{2}$ was prepared by heating a solution of $\left(\mathrm{NH}_{4}\right)_{2}\left[\mathrm{MoS}_{4}\right]$ in methanol containing $\mathrm{N}_{2} \mathrm{H}_{4} \cdot \mathrm{H}_{2} \mathrm{O}$ and poly(vinylpyrrolidone) in an autoclave at temperatures from 373 to $473 \mathrm{~K}$ for 3 hours. The amorphous nature of the $\mathrm{MoS}_{2}$ nanoparticles was indicated by selected area electron diffraction. Photocatalytic reactions were carried out in a solution containing $\mathrm{Ru}(\mathrm{bpy})_{3}{ }^{2+}$ as a photosensitizer and ascorbic acid as a sacrificial agent under visible light irradiation. A turnover number (TON) of 75 (based on catalyst) was found for this system. When $\mathrm{K}_{2} \mathrm{PtCl}_{4}$ was used instead of colloidal $\mathrm{MoS}_{2}$ nanoparticles, the TON was 26.

Recently, a photodeposition-based technique was applied to form $\mathrm{MoS}_{2}$ nanocrystals on $\mathrm{TiO}_{2}$ using an aqueous ethanol solution of $\left(\mathrm{NH}_{4}\right)_{2}\left[\mathrm{MoS}_{4}\right]^{35}$ The resulting $\mathrm{MoS}_{2} / \mathrm{TiO}_{2}$ photocatalyst exhibited activity for hydrogen generation in an aqueous solution of formic acid. It was found that $\mathrm{MoS}_{2}$ acted as a stable

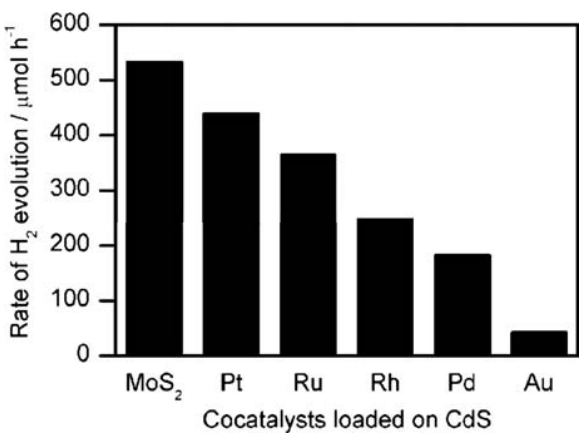

Fig. 6 Rate of photocatalytic hydrogen evolution on CdS loaded with $0.2 \mathrm{wt} \%$ of different cocatalysts. (Reprinted with permission from ref. 28. Copyright 2008 American Chemical Society.) 
catalyst under irradiation in this reaction. $\mathrm{MoS}_{2} / \mathrm{TiO}_{2}$ was found to perform 73 turnovers during 5 hours.

The incomplete cubane-like $\left[\mathrm{Mo}_{3} \mathrm{~S}_{4}\right]^{4+}$ clusters discussed in Section 3 were recently reported as catalyst on a silicon photocathode for solar hydrogen evolution. ${ }^{36}$ A solution of the clusters in a $1: 1$ mixture of dichloromethane and methanol was dropcast onto H-terminated planar $\mathrm{Si}(100)$ or pillar-structured $\mathrm{Si}$ (100) electrodes. The solvent was evaporated by heating the electrodes to $333 \mathrm{~K}$. The samples were used for photoelectrochemical measurements immediately after the deposition. The modified pillar-structured $\mathrm{Si}(100)$ sample $\left(\mathrm{Mo}_{3} \mathrm{~S}_{4} / \mathrm{Si}\right.$ pillars $)$ showed a higher photoelectrocatalytic activity than the modified plane $\mathrm{Si}(100)$ sample $\left(\mathrm{Mo}_{3} \mathrm{~S}_{4} / \mathrm{Si}\right.$ planar). In aqueous $1.0 \mathrm{M}$ $\mathrm{HClO}_{4}$ solution and under red-light irradiation, $\mathrm{Mo}_{3} \mathrm{~S}_{4} / \mathrm{Si}$ pillars revealed an onset potential for HER at $+0.15 \mathrm{~V}$ vs. RHE. The positive onset potential can be understood by considering the photovoltage of $\mathrm{p}-\mathrm{Si}$, which is approximately $0.55 \mathrm{~V} \cdot{ }^{38}$ Taking this photovoltage into account, the positive onset potential of $0.15 \mathrm{~V} v s$. RHE corresponds to an electrochemical overpotential of $c a .0 .4 \mathrm{~V}$. This value was also found in DFT computations as the required overpotential for electrochemical hydrogen evolution on $\left[\mathrm{Mo}_{3} \mathrm{~S}_{4}\right]^{4+}$ clusters. ${ }^{36}$ At $0 \mathrm{mV}$ the current density was $c a$. $9.5 \mathrm{~mA} \mathrm{~cm}^{-2}$ and the limiting current density of $c a .14 \mathrm{~mA} \mathrm{~cm}^{-2}$ was reached at $-0.3 \mathrm{~V}$ vs. RHE, which corresponds to an incident photon-to-current conversion efficiency (IPCE) of $c a .82 \%$ in this particular system. The hydrogen generation was shown to be stable during a photoelectrolysis experiment of 1 hour at $0 \mathrm{mV}$. The current efficiency was proved to be quantitative with gas chromatographic product quantification during the photoelectrolysis. A TOF of $65 \mathrm{~s}^{-1}$ was found. The bare $\mathrm{Si}(100)$ samples without $\left[\mathrm{Mo}_{3} \mathrm{~S}_{4}\right]^{4+}$ co-catalyst showed remarkably lower photoelectrocatalytic activity. All samples, i.e. the bare and the modified $\mathrm{Si}(100)$ samples, were not active in the dark. This result indicates that the deposited $\mathrm{Mo}_{3} \mathrm{~S}_{4}$ itself is not a good electrocatalyst.

\section{Amorphous $\mathrm{MoS}_{x}$ films}

\subsection{Synthesis and characterization}

Different methods to deposit amorphous molybdenum sulfide films have been reported. Electrodeposition from an aqueous solution of $\left(\mathrm{NH}_{4}\right)_{2}\left[\mathrm{MoS}_{4}\right]$ leads to amorphous $\mathrm{MoS}_{3}$ films at anodic potentials. ${ }^{39}$ If a cathodic potential is applied, amorphous $\mathrm{MoS}_{2}$ films are formed under electrolysis conditions. ${ }^{40}$ Electrodeposition in nonaqueous solvents has also been reported. ${ }^{41}$ Furthermore, amorphous $\mathrm{MoS}_{2}$ films can be prepared by chemical bath deposition by mixing a solution of $\left(\mathrm{NH}_{4}\right)_{2}\left[\mathrm{MoS}_{4}\right]$ with an ammonia solution and using hydrazine hydrate as a reducing agent. ${ }^{42}$ However, none of these films were tested for their ability to catalyze HER.

Our group recently published an easy and scalable way to deposit amorphous $\operatorname{MoS}_{x}$ films ( $x=2$ and 3$) .{ }^{37}$ The deposition takes place during consecutive cyclic voltammetry measurements in an aqueous solution of $\left(\mathrm{NH}_{4}\right)_{2}\left[\mathrm{MoS}_{4}\right]$. Typically, 25 consecutive cyclic voltammograms (CVs) between +0.1 and $-1.0 \mathrm{~V}$ vs. $\mathrm{Ag} / \mathrm{AgCl}$ are performed for the film formation. The deposition works on various conducting substrates such as FTO, ITO, and glassy carbon. The thicknesses of the films are in the order of 30
$130 \mathrm{~nm}$. The thickness of the films can be controlled by the number of $\mathrm{CV}$ scan cycles. The deposition can be started and terminated at either anodic $(+0.1 \mathrm{~V} v s . \mathrm{Ag} / \mathrm{AgCl})$ or cathodic $(-1.0 \mathrm{~V}$ vs. $\mathrm{Ag} / \mathrm{AgCl})$ potentials. Both methods lead to films with identical catalytic activity for HER (vide infra), but XPS studies showed that they are different in chemical composition.

When the CVs during the deposition were started and terminated at an anodic potential, i.e. the deposition ended with an oxidation process, the freshly prepared film is $\mathrm{MoS}_{3}$. When the deposition was terminated at a cathodic potential with a reduction process, the freshly prepared film is $\mathrm{MoS}_{2}$. Fig. 7 shows transmission and scanning electron microscopy (TEM and SEM) images of a $\mathrm{MoS}_{3}$ film on ITO. The film is X-ray amorphous and no electron diffraction pattern is observable. The $\mathrm{MoS}_{2}$ film has a similar morphology. The amorphous $\mathrm{MoS}_{3}$ and $\mathrm{MoS}_{2}$ films are very active catalysts for HER. The catalytic activity and the stability of the two films are identical. It is shown that the active form is the same, and is amorphous $\mathrm{MoS}_{2}$. For the $\mathrm{MoS}_{3}$ film, a reduction to $\mathrm{MoS}_{2}$ occurred before hydrogen evolution. In the following sections, a $\mathrm{MoS}_{3}$ film refers to a film with a composition of $\mathrm{MoS}_{3}$ when it is freshly prepared. When considering the HER activity, such film is equivalent to a $\mathrm{MoS}_{2}$ film.

\subsection{HER activity}

Tafel analysis of polarization measurements of $\mathrm{MoS}_{3}$ films in $1.0 \mathrm{M} \mathrm{H}_{2} \mathrm{SO}_{4}$ yielded exchange current densities between $1.5 \times$ $10^{-7}$ and $0.4 \times 10^{-7} \mathrm{~A} \mathrm{~cm}_{\text {geometric }}^{-2}$ and Tafel slopes in the range of $40 \mathrm{mV} \mathrm{dec}{ }^{-1}$. The TOF numbers per active site were determined for $\mathrm{MoS}_{3}$ films. Five films were made employing 6, 9, 12, 15 and 18 consecutive CVs. Polarization curves were measured in $\mathrm{pH}=$ 0 (Fig. 8A). The catalytic activity of the films increases with increasing numbers of repeated CVs. A thicker film is produced

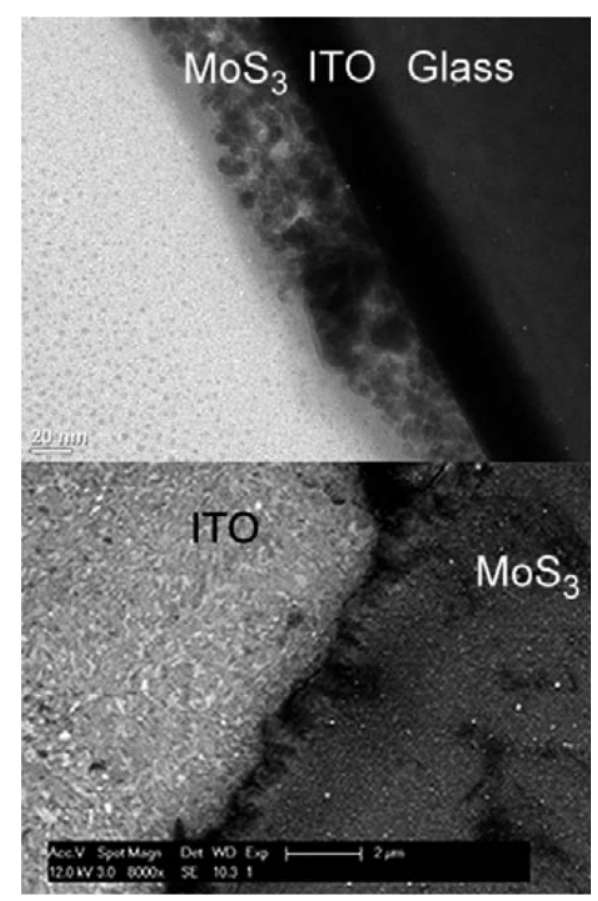

Fig. 7 Electron micrographs of an amorphous $\mathrm{MoS}_{x}$ film on ITO. (Reprinted from ref. 37.) 
with a higher number of scan cycles, and therefore, the catalytic activity of a film depends on the thickness of the film. The number of the electrochemically active sites for each film was determined by analyzing its cyclic voltammogram in $\mathrm{pH} 7$ phosphate buffer. The absolute components of the voltammetric charge (cathodic and anodic) reported during this single $\mathrm{CV}$ measurement were added up. Assuming a one electron redox process, this absolute charge was divided by two. The value was further divided by the Faraday constant to get the number of active sites for the film. The currents in the polarization measurement were then normalized by the number of active sites for each film. Dividing the normalized current by the Faraday constant and multiplying it by a factor of $1 / 2$ (to take into account that two electrons are required to form one hydrogen molecule from two protons) leads to TOF numbers per active site. The TOFs are nearly identical for all five films up to $250 \mathrm{mV}$ overpotential (Fig. 8B). This result indicates that HER occurs in the bulk of the film, not just at the surface. Platinum has a TOF of $0.9 \mathrm{~s}^{-1}$ at $0 \mathrm{mV}$ overpotential and $\mathrm{pH}=$ $0 .{ }^{18}$ To reach the same value, amorphous $\operatorname{MoS}_{x}$ films need an overpotential of $c a .220 \mathrm{mV}$.

Linear sweep voltammograms were measured in different $\mathrm{pHs}$ for a $\mathrm{MoS}_{3}$ film on a rotating disk electrode. Fig. 9 shows polarization curves performed at $\mathrm{pH} 0,1,2$ and 5 with a rotating rate of $4500 \mathrm{rpm}$. At low overpotentials $(\eta<250 \mathrm{mV})$, the current does not depend on the rotating rate and is therefore kineticcontrolled. The apparent geometric current densities decrease with higher $\mathrm{pHs}$, but the observed onset overpotential for hydrogen evolution seems to be the same over these pHs. At
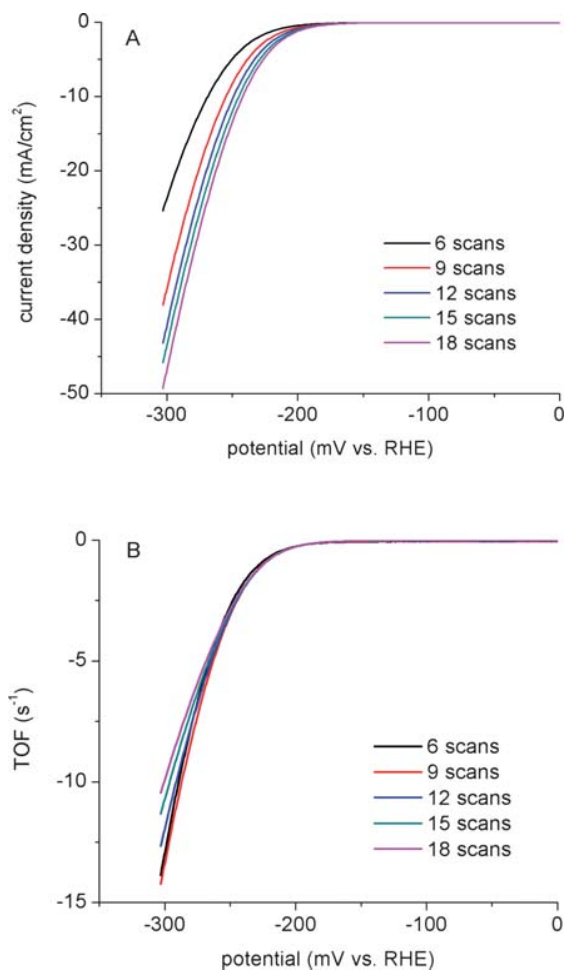

Fig. 8 (A) Polarization curves of amorphous $\mathrm{MoS}_{x}$ films on a glassy carbon made from different numbers of consecutive deposition CVs in $1.0 \mathrm{M} \mathrm{H}_{2} \mathrm{SO}_{4} ; 1 \mathrm{mV} \mathrm{s}^{-1}$. (B) Calculated turnover frequencies for the amorphous $\mathrm{MoS}_{x}$ films in $1.0 \mathrm{M} \mathrm{H}_{2} \mathrm{SO}_{4}$. (Reprinted from ref. 37.)

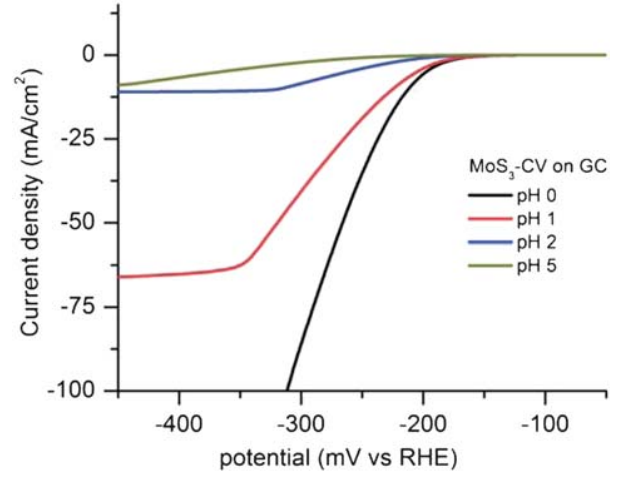

Fig. 9 Polarization curves of amorphous $\mathrm{MoS}_{x}$ films on a rotating glassy carbon disk electrode at $\mathrm{pH} 0,1,2$, and $5 ; 2 \mathrm{mV} \mathrm{s}^{-1}, 4500 \mathrm{rpm}$. (Reprinted from ref. 37.)

$\mathrm{pH}=0$, the current densities at 150,200 and $300 \mathrm{mV}$ overpotential are $c a$. $0.4,6$ and $86 \mathrm{~mA} \mathrm{~cm}_{\text {geometric, }}^{-2}$, respectively. Electrolysis at 200 and $300 \mathrm{mV}$ overpotentials gave a static current density of $c a .14$ and $160 \mathrm{~mA} \mathrm{~cm}-2$ geometric, respectively. The current efficiency during electrolysis measurements was shown to be quantitative. Fig. 10 shows the hydrogen amount produced over one hour in an electrolysis experiment at $200 \mathrm{mV}$ overpotential in $1.0 \mathrm{M} \mathrm{H}_{2} \mathrm{SO}_{4}$. The experimental line (black) overlays well with the calculated hydrogen production according to the cumulative charge, assuming a 100\% Faraday's yield (red). This experiment also shows that the $\mathrm{MoS}_{3}$ catalyst is stable during the electrolysis.

\subsection{Stability}

$\mathrm{Pt}$ is a superior HER catalyst. A freshly activated Pt electrode is extremely active. $\mathrm{Pt}$ is, however, sensitive to trace of impurities and ion adsorption. The activity of Pt decreased gradually but substantially during consecutive polarization measurements (Fig. S1A, ESI $\dagger$ ). Contrary to Pt, amorphous $\mathrm{MoS}_{3}$ films exhibited the same catalytic activity during consecutive polarization measurements (Fig. S1B, ESI $\dagger$ ). Electrolysis experiments also showed that the current density remained constant for hours using $\mathrm{MoS}_{3}$ catalyst.

$\mathrm{CO}$ is a known inhibitor of $\mathrm{Pt}$ because $\mathrm{CO}$ can bind to the electron-rich $\operatorname{Pt}(0)$ surface. Fig. $11 \mathrm{~A}$ shows that the presence of $\mathrm{CO}$ gas completely shut down HER by freshly activated Pt

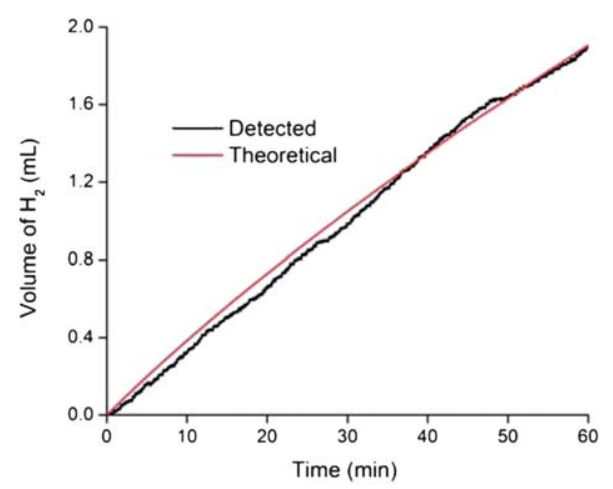

Fig. 10 Current efficiency for hydrogen production catalyzed by an amorphous $\mathrm{MoS}_{x}$ film on a glassy carbon in $1.0 \mathrm{M} \mathrm{H}_{2} \mathrm{SO}_{4}$ and at $200 \mathrm{mV}$ overpotential (see main text for details). (Reprinted from ref. 37.) 
electrodes. In contrast, $\mathrm{CO}$ did not seem to inhibit the catalytic activity of the $\mathrm{MoS}_{3}$ film. Injecting a significant amount of $\mathrm{CO}$ into the electrochemical cell did not result in an appreciable change in the HER activity of the $\mathrm{MoS}_{3}$ film (Fig. 11B).

Similar phenomena were observed with external $\mathrm{CO}_{2}$. The activity of $\mathrm{Pt}$ was diminished in the presence of $\mathrm{CO}_{2}$, albeit to a less degree than with CO (Fig. S2A, ESI $\dagger$ ). The activity of $\mathrm{MoS}_{3}$, on the other hand, was completely unaffected by $\mathrm{CO}_{2}$ (Fig. S2B, ESI $\dagger$ ).

The stability of the $\mathrm{MoS}_{3}$ film against $\mathrm{CO}$ and $\mathrm{CO}_{2}$ does not have a practical advantage in terms of HER because these two gases do not pose a problem under normal conditions. However, this stability offers insight into the nature of the catalytic species. For $\mathrm{Pt}$ metal, it is assumed that $\operatorname{Pt}(0)$ is responsible for catalysis. This $\operatorname{Pt}(0)$ is highly reduced and common $\pi$-acceptor ligands like $\mathrm{CO}$ and $\mathrm{CO}_{2}$ will bind. As a result, $\mathrm{Pt}$ is poisoned by these gases. Because amorphous $\mathrm{MoS}_{3} / \mathrm{MoS}_{2}$ films are not poisoned by $\mathrm{CO}$ or $\mathrm{CO}_{2}$, the catalytically active species are therefore not highly reduced Mo metal centers. This hypothesis is further confirmed by the stability of the $\mathrm{MoS}_{3}$ catalyst against air (Fig. S3, ESI $\dagger$ ). A low-valent Mo center will not be stable in air. Therefore, we propose that the sulfur ligands play an important role in catalysis. This will be explained and discussed in the following subsection.

\subsection{Why does amorphous $\mathrm{MoS}_{2}$ work?}

The DFT studies ${ }^{15}$ showed that Mo (1010) edge sites with $50 \% \mathrm{~S}$ adsorption are active for HER because the adsorbed sulfur atoms at the edge are unsaturated. As a result, $\mathrm{H}$ atoms can adsorb on these sulfur atoms, and the free energy of adsorption $\left(\Delta G_{\mathrm{H}}\right)$ is small. This makes the edge sites of $\mathrm{MoS}_{2}$ nanoparticles good catalysts. This hypothesis was confirmed by experiment. ${ }^{18}$ Consequently, there is a lot of interest in developing methods to maximize the edge sites of $\mathrm{MoS}_{2}$ nanoparticles.

The amorphous $\mathrm{MoS}_{2}$ film is lacking of such well-defined Mo (1010) edge sites. One would expect that it is not active at all for HER. Yet it is among the most active $\mathrm{MoS}_{2}$-based catalysts (see Section 6 for a comparison). We hypothesize that the activity is
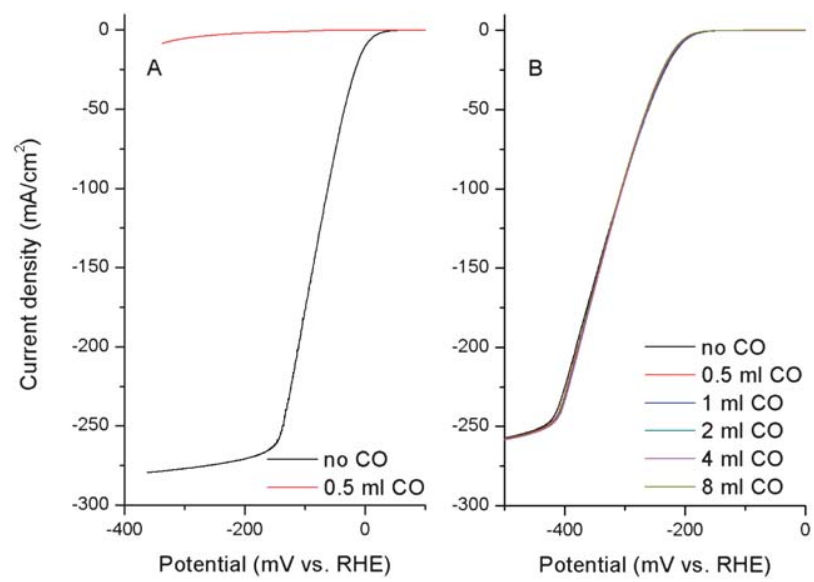

Fig. 11 Polarization curves with a platinum rotating disk electrode (A) and with amorphous $\mathrm{MoS}_{3}$ on a rotating glassy carbon disk electrode (B) before and after the injection of $\mathrm{CO}$ into the solution $\left(1.0 \mathrm{M} \mathrm{H}_{2} \mathrm{SO}_{4}\right) ; 2$ $\mathrm{mV} \mathrm{s}^{-1}, 4500 \mathrm{rpm}$. due to unsaturated sulfur atoms. The amorphous $\mathrm{MoS}_{2}$ has many defect sites, and at these sites, there are many coordinately and structurally unsaturated sulfur atoms. Hydrogen can adsorb on these sulfur atoms which eventually leads to hydrogen evolution. The involvement of sulfur ligands is reflected in the stability of the $\mathrm{MoS}_{2}$ film against $\mathrm{CO}, \mathrm{CO}_{2}$, and $\mathrm{O}_{2}$. Because the redox chemistry occurs mainly at the sulfur sites, the Mo centers are not reduced to a lower oxidation state which would be poisoned by these gases. Mechanistically, HER by amorphous $\mathrm{MoS}_{2}$ might be similar to that by incomplete cubane-type $\left[\mathrm{Mo}_{3} \mathrm{~S}_{4}\right]^{4+}$ catalysts. We are currently developing coordination complexes featuring unsaturated sulfur ligands to probe the mechanism at a molecular level.

\section{Comparison of different $M_{0} S_{x}$ and $\mathrm{WS}_{2}$ HER catalysts}

\subsection{Catalytic activity}

One important quality of a catalyst is its activity. For HER, one parameter to quantify the catalytic activity is the exchange current density, i.e. the current density at the thermodynamic redox potential. A comparison of the exchange current densities $\left(j_{0}\right)$ of the various molybdenum sulfide catalysts discussed in the previous sections shows that their $j_{0}$ are of the same order of magnitude (Table 1). However, the correlation of $j_{0}$ with activity for different catalysts is not straightforward, because the $j_{0}$ values are often obtained by various extrapolation methods and are subject to significant errors. Furthermore, it is hard to compare $j_{0}$ for catalysts with different Tafel slopes and reaction mechanism. In terms of TOF, the edge site of $\mathrm{MoS}_{2}$ nanocrystals is most active, followed by the incomplete cubane-type $\left[\mathrm{Mo}_{3} \mathrm{~S}_{4}\right]^{4+}$, and then amorphous $\operatorname{MoS}_{x}$ (Table 1).

In the context of practical applications, the activity of a catalyst is better measured by the geometric current density at the same working potential, which has a certain amount of overpotential. With similar levels of loading, the amorphous $\mathrm{MoS}_{x}$ film gave the highest current density at $\eta=300 \mathrm{mV}$, thanks to its small Tafel slope (vide infra). With a significantly higher amount of catalyst loading, the $\mathrm{MoS}_{2} / \mathrm{RGO}$ system gave the highest absolute geometric current density at $\eta=150 \mathrm{mV}$. The activity per site, however, does not seem to be higher than other $\operatorname{MoS}_{x}$ catalysts.

The reported Tafel slopes vary significantly between the $\mathrm{MoS}_{x}$ and $\mathrm{WS}_{2}$ catalysts (Table 1). Tafel analysis allows the distinction of possible mechanisms for HER. In acid solutions, three reactions are assumed to predominate when hydrogen is evolved on a metal catalyst: ${ }^{43,44}$

$$
\begin{aligned}
& \text { discharge reaction: } \mathrm{H}_{3} \mathrm{O}^{+}+\mathrm{e}^{-}+\text {cat } \rightleftharpoons \text { cat- } \mathrm{H}+\mathrm{H}_{2} \mathrm{O} \\
& \text { combination reaction: cat- } \mathrm{H}+\text { cat- } \mathrm{H} \rightleftharpoons 2 \text { cat }+\mathrm{H}_{2}
\end{aligned}
$$

ion + atom reaction: $\mathrm{H}_{3} \mathrm{O}^{+}+\mathrm{e}^{-}+$cat- $\mathrm{H} \rightleftharpoons$ cat $+\mathrm{H}_{2}+\mathrm{H}_{2} \mathrm{O}(3)$

A fast discharge reaction (1) followed by a rate-determining

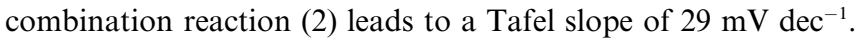
When (1) is fast and is followed by a slow ion + atom reaction (3), a Tafel slope of $38 \mathrm{mV} \mathrm{dec}^{-1}$ is obtained. If (1) is rate-determining or the surface coverage is close to one, the Tafel slope is $116 \mathrm{mV}$ 
Table 1 Catalyst loadings, exchange current densities, Tafel slopes, turnover frequencies and current densities at given overpotentials for different $\mathrm{MoS}_{x}$ and $\mathrm{WS}_{2}$ catalysts

\begin{tabular}{|c|c|c|c|c|c|c|}
\hline Catalyst type & $\begin{array}{l}\text { Catalyst loading/ } \\
\mu \mathrm{g} \mathrm{cm}^{-2}\end{array}$ & $j_{0} / \mathrm{A} \mathrm{cm}_{\text {geometric }}^{-2}$ & $\begin{array}{l}\text { Tafel slope/ } \\
\mathrm{mV} \mathrm{dec}^{-1}\end{array}$ & $\mathrm{TOF}^{b} / \mathrm{s}^{-1}$ & $\begin{array}{l}j \text { at } \eta=150 \mathrm{mV} \\
\left(\mathrm{mA} \mathrm{cm}_{\text {geometric }}^{-2}\right)^{c}\end{array}$ & $\begin{array}{l}j \text { at } \eta=300 \mathrm{mV} \\
\left(\mathrm{mA} \mathrm{cm}_{\text {geometric }}^{-2}\right)^{c}\end{array}$ \\
\hline $\begin{array}{l}\text { Nanoparticulate } \mathrm{MoS}_{2} \\
\text { (Jaramillo et al.) }\end{array}$ & - & $1.3-3.1 \times 10^{-7}$ & $55-60$ & 0.02 at $\eta=0 \mathrm{mV}$ & 0.2 & - \\
\hline $\begin{array}{l}\text { Nanoparticulate } \mathrm{MoS}_{2} \\
\text { (Bonde } \text { et } \text { al.) }\end{array}$ & $4^{a}$ & $4.6 \times 10^{-6}$ & 120 & - & $0^{d}$ & 1.5 \\
\hline Nanoparticulate $\mathrm{WS}_{2}$ & $5^{a}$ & - & 135 & - & - & $1.0^{e}$ \\
\hline Co promoted $\mathrm{MoS}_{2}$ & $9^{a}$ & - & 101 & - & - & $4^{e}$ \\
\hline$\left[\mathrm{Mo}_{3} \mathrm{~S}_{4}\right]^{4+}$ & 0.0067 & $2.2 \times 10^{-7}$ & 120 & 0.07 at $\eta=0 \mathrm{mV}$ & $2.5^{e}$ & $16.5^{e}$ \\
\hline Amorphous $\mathrm{MoS}_{x}$ & 9 & $0.4-1.5 \times 10^{-7}$ & 40 & 0.9 at $\eta=220 \mathrm{mV}$ & 0.4 & $160^{f}$ \\
\hline
\end{tabular}

${ }^{a}$ Estimated values on the basis of the description of electrode preparations. ${ }^{b}$ Platinum reveals a TOF of $0.9 \mathrm{~s}^{-1}$ at $0 \mathrm{mV}$ overpotential. ${ }^{c}$ Most of these values are estimations on the basis of polarization curves. ${ }^{d}$ A current density of $0.3 \mathrm{~mA} \mathrm{~cm}{ }^{-2}$ was observed which is not due to HER but oxygen reduction. HER occurs at $\eta=200 \mathrm{mV}$. ${ }^{e}$ During the initial polarization curve. ${ }^{f}$ From electrolysis experiment.

$\mathrm{dec}^{-1}$. Although the correlation between the HER mechanism and the measured Tafel slope was reported with metal catalysts, ${ }^{43,44}$ it is helpful to analyze the different Tafel slopes found for the $\mathrm{MoS}_{x}$ and $\mathrm{WS}_{2}$ catalysts. Hydrogen evolution on amorphous $\mathrm{MoS}_{2}$ and $\mathrm{MoS}_{3}$ films as well as on $\mathrm{MoS}_{2} / \mathrm{RGO}$ most probably goes via a fast discharge reaction and a rate-determining ion + atom reaction. The Tafel slope for nanoparticulate $\mathrm{MoS}_{2}$ reported by Jaramillo et al. is $60 \mathrm{mV} \mathrm{dec}{ }^{-1}$. According to Thomas, ${ }^{44}$ a Tafel slope of $60 \mathrm{mV} \mathrm{dec}^{-1}$ can arise when the chemisorption of hydrogen from aqueous solution requires an activation energy. The mechanism is then a fast discharge reaction (1) followed by either a rate-determining combination (2) or a rate-determining ion + atom reaction (3). The two possible mechanisms cannot be distinguished by Tafel analysis alone. On most metal electrodes, the chemisorption of hydrogen requires no activation energy and the observed Tafel slopes are close to 30,40 , or $120 \mathrm{mV} \mathrm{dec}^{-1}$. The high Tafel slopes observed for the incomplete cubane-type $\left[\mathrm{Mo}_{3} \mathrm{~S}_{4}\right]^{4+}$ as well as nanoparticulate $\mathrm{MoS}_{2}$ and $\mathrm{WS}_{2}$ reported by Bonde et al. show either a surface coverage close to one or a slow discharge reaction. This analysis is, of course, based on the assumption that the Tafel slopes are always obtained correctly, and the influence of electron transfer to the electrode, substrate diffusion, and uncompensated resistance is taken into account properly.

For practical applications, a small Tafel slope is advantageous because it will lead to a faster increase of HER rate with the increase of overpotentials.

\subsection{Cost and scalability}

Molybdenum and tungsten sulfides are interesting HER catalysts because they are made of more abundant and economical materials than Pt-based catalysts. In principle, they are less costly and more scalable. However, the overall cost of the catalyst depends on its preparative methods. In this sense, the $\mathrm{MoS}_{2}$ nanocrystals deposited on $\mathrm{Au}(111)$ are quite precious because they are made by deposition of high purity Mo on a clean $\mathrm{Au}$ surface followed by sulfiding at high temperature with $\mathrm{H}_{2} \mathrm{~S}$. Promoted and unpromoted $\mathrm{MoS}_{2} / \mathrm{WS}_{2}$ nanoparticles on carbon are made from cheaper metal salts as starting materials and can be scaled up. The drawback is that a high-temperature sulfiding procedure is needed, which is energy intensive and requires an investment in equipment. The $\left[\mathrm{Mo}_{3} \mathrm{~S}_{4}\right]^{4+}$ catalysts adsorbed on carbon can be easily prepared. However, it is shown that the modified electrodes lose HER activity quickly because $\left[\mathrm{Mo}_{3} \mathrm{~S}_{4}\right]^{4+}$ desorbs from the surface. Improvement in the stability of the $\left[\mathrm{Mo}_{3} \mathrm{~S}_{4}\right]^{4+} / \mathrm{C}$ hybrid system will make it more appealing for practical applications. The $\mathrm{MoS}_{2} / \mathrm{RGO}$ system is made of $\mathrm{MoS}_{2}$ synthesized solvothermally and rather expensive RGO, therefore its application seems limited at this time. The amorphous $\operatorname{MoS}_{x}$ films are made by simple electropolymerization of cheap metal sulfides at room temperature and ambient pressure. The deposition is simple, rapid, and requires no sophisticate equipment. Thanks to a small Tafel slope, it displays a high activity at a reasonable overpotential. For these reasons, we believe the $\mathrm{MoS}_{x}$ films compare favorably to other $\mathrm{MoS}_{x} / \mathrm{WS}_{2}$ systems in terms of activity, cost, and scalability.

\section{Conclusions}

Nanoparticulate and amorphous molybdenum and tungsten sulfide materials show good catalytic activity in hydrogen evolution. They can be synthesized and/or deposited on various conductive materials. Doping with transition metals, e.g. cobalt or nickel, can alter the structure and eventually enhance the catalytic ability or the stability of the catalyst. The fact that these sulfide catalysts can be synthesized from relatively abundant materials, together with their good catalytic performances, makes them promising candidates for use in hydrogen production technologies. As most of these materials display comparable exchange current densities, the production cost and scalability of a given catalyst become determining factors for applications. The understanding of the HER mechanism by $\mathrm{MoS}_{2}$ at the molecular level may guide the design of better catalysts. Synthetic chemistry has an important role to play in this field, by developing the most economical and scalable processes, and by providing models for mechanistic studies.

Molybdenum sulfide has been successfully used as a catalyst in photocatalytic hydrogen production, when mixed with an appropriate photosensitizer or semiconductor. This opens a wide 
field for applications of these catalysts in solar energy conversion. Whereas it is shown that a good photocatalyst is not necessarily a good electrocatalyst, ${ }^{36}$ when a good electrocatalyst is used for photoelectrocatalysis, a higher activity and/or efficiency is expected. The various active $\mathrm{MoS}_{2}$ and $\mathrm{WS}_{2}$ materials described herein are therefore promising catalysts for photoelectrochemical water splitting.

However, long-term studies with molybdenum or tungsten sulfide catalysts, either in electrocatalysis or photocatalysis, have not been done yet. This means that despite encouraging results in a lab scale, only experiments with appropriately designed devices will show the real potential of these catalysts in large scale applications.

\section{Experimental}

\subsection{Chemicals and reagents}

All manipulations were carried out under an inert $\mathrm{N}_{2}(\mathrm{~g})$ atmosphere using glovebox techniques unless otherwise mentioned. Unless noted, all other reagents were purchased from commercial sources and used without further purification.

\subsection{Physical methods}

Electrochemical measurements were recorded by an IviumStat electrochemical analyzer or an EG\&G Princeton Applied Research Potentiostat/Galvanostat model 273. A three-electrode configuration was used. For polarization measurements, a platinum wire was used as the auxiliary electrode and an $\mathrm{Ag} / \mathrm{AgCl}$ ( $\mathrm{KCl}$ saturated) electrode was used as the reference electrode. The reference electrode was placed in a position very close to the working electrode with the aid of a Luggin tube. The auxiliary electrode compartment was separated by a glass frit from the working electrode compartment. For rotating disk measurements, an Autolab Rotating Disk Electrode assembly was used. Potentials were referenced to reversible hydrogen electrode (RHE) by adding a value of $(0.197+0.059 \mathrm{pH}) \mathrm{V}$.

\subsection{Electrodes and deposition of $\mathrm{MoS}_{3}$ films}

A $3 \mathrm{~mm}$ diameter glassy carbon rotating disk working electrode from Autolab (6.1204.300 GC) was used.

The electrode was polished with two different Alpha alumina powder (1.0 and 0.3 micron from $\mathrm{CH}$ Instruments) suspended in distilled water on a Nylon polishing pad ( $\mathrm{CH}$ Instruments) and with Gamma alumina powder (0.05 micron from $\mathrm{CH}$ Instruments) suspended in distilled water on a Microcloth polishing pad ( $\mathrm{CH}$ Instruments). Before going to the next smaller powder size and at the end of polishing, the electrodes were thoroughly rinsed with distilled water.

The modification was carried out in a glovebox under nitrogen. The freshly polished electrode was immersed into a 2 $\mathrm{mM}$ solution of $\left(\mathrm{NH}_{4}\right)_{2}\left[\mathrm{MoS}_{4}\right]$ in $0.1 \mathrm{M} \mathrm{NaClO}_{4}$ in water $(8 \mathrm{~mL})$. Both chemicals were used as received (Aldrich). Thirty consecutive cyclic voltammograms were carried out on an Ivium Stat potentiostat (Ivium Technologies) with a saturated silver/silver chloride reference electrode (separated by a porous vycor tip) and a titanium wire counter electrode. The cyclic voltammograms were performed between +0.1 and $-1.0 \mathrm{~V}$ vs. $\mathrm{Ag} / \mathrm{AgCl}$ (sat.) and a scan rate of $0.05 \mathrm{~V} \mathrm{~s}^{-1}$ was employed. Finally, the modified electrode was rinsed with distilled water.

For the measurements with a platinum working electrode, a 3 $\mathrm{mm}$ diameter platinum rotating disk working electrode from Autolab (6.1204.310 Pt) was used.

\subsection{Electrochemical measurements}

Consecutive polarization measurements under nitrogen. Polarization measurements were carried out in $1.0 \mathrm{M} \mathrm{H}_{2} \mathrm{SO}_{4}$. The platinum electrode was polarized from +0.20 to $-0.56 \mathrm{~V} v \mathrm{~s}$. $\mathrm{Ag} /$ $\mathrm{AgCl}$. The modified glassy carbon electrode was polarized from 0 to $-0.7 \mathrm{~V}$ vs. $\mathrm{Ag} / \mathrm{AgCl}$. The scan rate was $2 \mathrm{mV} \mathrm{s}^{-1}$ and an equilibration time of $10 \mathrm{~s}$ was chosen. The electrode was rotating with $4500 \mathrm{rpm}$. Previous to the first scan, the platinum electrode was activated by sweeping the potential from +2.0 to $-0.5 \mathrm{~V} v s$. $\mathrm{Ag} / \mathrm{AgCl}\left(\mathrm{scan}\right.$ rate $\left.=50 \mathrm{mV} \mathrm{s}^{-1}\right)$.

Consecutive polarization measurements in air. Polarization measurements were carried out in $1.0 \mathrm{M} \mathrm{H}_{2} \mathrm{SO}_{4}$ outside the glovebox. Previous to each polarization scan, air was bubbled through the solution for one minute. The platinum electrode was polarized from +0.20 to $-0.50 \mathrm{~V}$ vs. $\mathrm{Ag} / \mathrm{AgCl}$. The modified glassy carbon electrode was polarized from 0 to $-0.7 \mathrm{~V} v s$. Ag/ $\mathrm{AgCl}$. The scan rate was $2 \mathrm{mV} \mathrm{s}^{-1}$ and an equilibration time of 10 $\mathrm{s}$ was chosen. The electrode was rotating with $4500 \mathrm{rpm}$. Previous to the first scan, the platinum electrode was activated by sweeping the potential from +2.0 to $-0.5 \mathrm{~V}$ vs. $\mathrm{Ag} / \mathrm{AgCl}$ (scan rate $\left.=50 \mathrm{mV} \mathrm{s}^{-1}\right)$.

Polarization measurements in the presence of $\mathrm{CO}$ and $\mathrm{CO}_{2}$. Polarization measurements were carried out in $1.0 \mathrm{M} \mathrm{H}_{2} \mathrm{SO}_{4}$ in a closed cell. The solution volume in the working electrode compartment was $c a .20 \mathrm{ml}$ and the headspace was $c a .15 \mathrm{ml}$. The platinum electrode was polarized from +0.20 to $-0.50(-0.56$ in the case of CO) $\mathrm{V} v$ s. $\mathrm{Ag} / \mathrm{AgCl}$. The modified glassy carbon electrode was polarized from 0 to $-0.7 \mathrm{~V} v s$. $\mathrm{Ag} / \mathrm{AgCl}$. The scan rate was $2 \mathrm{mV} \mathrm{s}^{-1}$ and an equilibration time of $10 \mathrm{~s}$ was chosen. The electrode was rotating with $4500 \mathrm{rpm}$. Volumes between 0.5 and $12 \mathrm{ml}$ of $\mathrm{CO}$ or $\mathrm{CO}_{2}$, respectively, were injected into the solution below the working electrode directly before starting the measurements. Previous to each scan and in the absence of $\mathrm{CO}$ or $\mathrm{CO}_{2}$, the platinum electrode was activated by sweeping the potential from +2.0 to $-0.5 \mathrm{~V} v$. $\mathrm{Ag} / \mathrm{AgCl}\left(\mathrm{scan}\right.$ rate $\left.=50 \mathrm{mV} \mathrm{s}^{-1}\right)$.

Note: to ensure that the catalytic properties of the $\mathrm{MoS}_{3}$ films are not due to Pt particles that can be accidently deposited during electrochemical experiments, polarization curves of these films were measured using $\mathrm{Ti}$ as the counter electrode as well. At overpotentials below $300 \mathrm{mV}$, the polarization curves are nearly identical to those measured using $\mathrm{Pt}$ as the counter electrode. Some discrepancy was found at higher overpotentials, probably because the Ti counter electrode is not able to supply enough current at those potentials. These results rule out the possibility of $\mathrm{Pt}$ contamination.

\section{Acknowledgements}

This work is supported by a starting grant from the European Research Council under the European Community's Seventh 
Framework Programme (FP7 2007-2013)/ERC Grant agreement no. 257096. We thank Heron Vrubel and Dr Stéphane Fierro for their contributions to our project on hydrogen evolution catalysis.

\section{Notes and references}

1 Climate Change 2007: Synthesis Report. Contribution of Working Groups I, II and III to the Fourth Assessment. Report of the Intergovernmental Panel on Climate Change, ed. R. Pachauri and A. Reisinger, IPCC, Geneva, 2008

2 G. W. Crabtree, M. S. Dresselhaus and M. V. Buchanan, Phys Today, 2004, 57, 39-44; J. A. Turner, Science, 2004, 305, 972-974.

3 N. S. Lewis and D. G. Nocera, Proc. Natl. Acad. Sci. U. S. A., 2006, 103, 15729-15735.

4 K. Shimura and H. Yoshida, Energy Environ. Sci., 2011, 4, 24672481.

5 P. M. Vignais, B. Billoud and J. Meyer, FEMS Microbiol. Rev., 2001, 25, 455-501.

6 T. R. Cook, D. K. Dogutan, S. Y. Reece, Y. Surendranath, T. S. Teets and D. G. Nocera, Chem. Rev., 2010, 110, 6474-6502, C. Tard and C. J. Pickett, Chem. Rev., 2009, 109, 2245-2274; M. R. DuBois and D. L. DuBois, Chem. Soc. Rev., 2009, 38, 6272; V. Artero and M. Fontecave, Coord. Chem. Rev., 2005, 249, $1518-1535$.

7 A. M. Appel, D. L. DuBois and M. R. DuBois, J. Am. Chem. Soc., 2005, 127, 12717-12726.

8 R. Prins, V. H. J. Debeer and G. A. Somorjai, Catal. Rev., 1989, 31, 1-41.

9 T. Spalvins, J. Vac. Sci. Technol., A, 1987, 5, 212-219.

10 W. Jaegermann and H. Tributsch, Prog. Surf. Sci., 1988, 29, 1-167.

11 The addition of molybdenum disulfide was known to enhance the catalytic activity of nickel sulfide HER cathodes in alkaline media (see ref. 12 and 13).

12 L. B. Albertini, A. C. D. Angelo and E. R. Gonzalez, J. Appl. Electrochem., 1992, 22, 888-892; A. Nidola and R. Schira, Int. J. Hydrogen Energy, 1986, 11, 449-454.

13 The same can be stated for tungsten disulfide, whose HER activity was first studied in 1988 by Sobczynski, et al. (ref. 14).

14 A. Sobczynski, A. Yildiz, A. J. Bard, A. Campion, M. A. Fox, T. Mallouk, S. E. Webber and J. M. White, J. Phys. Chem., 1988, 92, 2311-2315.

15 B. Hinnemann, P. G. Moses, J. Bonde, K. P. Jorgensen, J. H. Nielsen, S. Horch, I. Chorkendorff and J. K. Norskov, J. Am. Chem. Soc, 2005, 127, 5308-5309.

16 S. Helveg, J. V. Lauritsen, E. Laegsgaard, I. Stensgaard, J. K. Norskov, B. S. Clausen, H. Topsoe and F. Besenbacher, Phys. Rev. Lett., 2000, 84, 951-954.

17 J. V. Lauritsen, M. V. Bollinger, E. Laegsgaard, K. W. Jacobsen, J. K. Norskov, B. S. Clausen, H. Topsoe and F. Besenbacher, $J$. Catal., 2004, 221, 510-522.

18 T. F. Jaramillo, K. P. Jorgensen, J. Bonde, J. H. Nielsen, S. Horch and I. Chorkendorff, Science, 2007, 317, 100-102.

19 M. Daage and R. R. Chianelli, J. Catal., 1994, 149, 414-427.

20 J. Bonde, P. G. Moses, T. F. Jaramillo, J. K. Norskov and I. Chorkendorff, Faraday Discuss., 2009, 140, 219-231.
21 M. Brorson, A. Carlsson and H. Topsoe, Catal. Today, 2007, 123, $31-$ 36.

22 M. K. Agarwal, K. Nagireddy and H. B. Patel, J. Cryst. Growth, 1979, 46, 139-142.

23 L. S. Byskov, J. K. Norskov, B. S. Clausen and H. Topsoe, J. Catal., 1999, 187, 109-122; J. V. Lauritsen, S. Helveg, E. Laegsgaard, I. Stensgaard, B. S. Clausen, H. Topsoe and E. Besenbacher, J. Catal., 2001, 197, 1-5.

24 Y. Okamoto, K. Tamura and T. Kubota, Chem. Commun., 2010, 46, $2748-2750$

25 Y. Li, H. Wang, L. Xie, Y. Liang, G. Hong and H. Dai, J. Am. Chem. Soc., 2011, 133, 7296-7299.

26 T. F. Jaramillo, J. Bonde, J. D. Zhang, B. L. Ooi, K. Andersson, J. Ulstrup and I. Chorkendorff, J. Phys. Chem. C, 2008, 112, $17492-17498$.

27 J. C. Muijsers, T. Weber, R. M. vanHardeveld, H. W. Zandbergen and J. W. Niemantsverdriet, J. Catal., 1995, 157, 698-705; T. Weber, J. C. Muijsers and J. W. Niemantsverdriet, J. Phys. Chem., 1995, 99, 9194-9200.

28 X. Zong, H. J. Yan, G. P. Wu, G. J. Ma, F. Y. Wen, L. Wang and C. Li, J. Am. Chem. Soc., 2008, 130, 7176-7177.

29 Amorphous molybdenum sulfide films developed in our group (see Section 5) show as well no catalytic activity toward the HOR.

30 H. G. Park and J. K. Holt, Energy Environ. Sci., 2010, 3, 1028-1036.

31 M. D. Hernandez-Alonso, F. Fresno, S. Suarez and J. M. Coronado, Energy Environ. Sci., 2009, 2, 1231-1257.

32 A. Sobczynski, J. Catal., 1991, 131, 156-166.

33 Referred to $1 \mathrm{~g}$ catalyst and converted to volume, the hydrogen evolution rate is $c a .120 \mathrm{ml} \mathrm{h}^{-1}$.

34 X. Zong, Y. Na, F. Y. Wen, G. J. Ma, J. H. Yang, D. G. Wang, Y. Ma, M. Wang, L. Sun and C. Li, Chem. Commun., 2009, 45364538 .

35 S. Kanda, T. Akita, M. Fujishima and H. Tada, J. Colloid Interface Sci., 2011, 354, 607-610.

36 Y. D. Hou, B. L. Abrams, P. C. K. Vesborg, M. E. Bjorketun, K. Herbst, L. Bech, A. M. Setti, C. D. Damsgaard, T. Pedersen, O. Hansen, J. Rossmeisl, S. Dahl, J. K. Norskov and I. Chorkendorff, Nat. Mater., 2011, 10, 434-438.

37 D. Merki, S. Fierro, H. Vrubel and X. Hu, Chem. Sci., 2011, 2, 1262 1267.

38 S. W. Boettcher, J. M. Spurgeon, M. C. Putnam, E. L. Warren, D. B. Turner-Evans, M. D. Kelzenberg, J. R. Maiolo, H. A. Atwater and N. S. Lewis, Science, 2010, 327, 185-187.

39 D. Belanger, G. Laperriere and B. Marsan, J. Electroanal. Chem., 1993, 347, 165-183; G. Laperriere, B. Marsan and D. Belanger, Synth. Met., 1989, 29, F201-F206.

40 E. A. Ponomarev, M. NeumannSpallart, G. Hodes and C. LevyClement, Thin Solid Films, 1996, 280, 86-89.

41 A. Albu-Yaron, C. Levy-Clement and J. L. Hutchison, Electrochem. Solid-State Lett., 1999, 2, 627-630; E. A. Ponomarev, A. AlbuYaron, R. Tenne and C. LevyClement, J. Electrochem. Soc., 1997, 144, L277-L279.

42 P. Roy and S. K. Srivastava, Thin Solid Films, 2006, 496, 293-298.

43 J. O. M. Bockris and E. C. Potter, J. Electrochem. Soc., 1952, 99, 169186.

44 J. G. Thomas, Trans. Faraday Soc., 1961, 57, 1603-1611. 